\title{
Muzika u Team Building-u
}

\section{Mirjana Maksimović}

Sažetak: Muzika je moćan medijum i sve se više primenjuje u programima obuke u menadžmentu. Muzika je uvek bila sastavni deo kulture i tradicije primitivnih ljudi predstavljajući oblik društvene komunikacije. Jednostavn model koji ćemo ovde prikazati može biti koristan u odabiru muzike za trening menadžment timova. Pridržavajući se osnovnih principa, ovaj model možemo koristitii uz primene bilo koje vrste muzike, u zavisnosti od učesnika u radionici koja se sprovodi.

Ključne reči: Timski rad, muzika

Muzika je moćan medijum i sve se više primenjuje u programima obuke u menadžmentu. Muzika je uvek bila sastavni deo kulture i tradicije primitivnih ljudi. Mnoga plemena koriste muziku da inspirišu svoje ratnike, slave pobede, venčanja, rođenja i žale svoje mrtve.

U našoj kulturi muzika se koristi na sličan način. Sve nacije imaju himne koje sviraju u vremenima proslava i koje inspirišu nacionalni ponos. Trupe se ispraćaju u rat muzikom i dočekuju muzikom. Mnogi sportski timovi imaju himne koje njihovi obožavaoci pevaju inspirišući ih na pobedu. Mi smo se odlučili da koncept muzike primenimo u obuci za timski rad.

Aplikativna muzika nije novijeg datuma. Danas poznajemo više tipova aplikativne muzike, a u zavisnosti od učinka koji želimo postići odlučujemo se za neki od mogućih tipova. Poznato je da muzika na radnom mestu, 
nesumnjivo, podstiče produktivnost, smanjuje stres, minimizira buku i doprinosi osećaju privatnosti. Kao primer možemo izdvojiti američki Pentagon na primer, koji je potvrdio da muzika povećava pažnju i efikasnost. Oni tvrde da su operateri na položajima za ispaljivanje raketa za vreme hladnog rata za $29 \%$ brže i preciznije ispaljivali rakete kada su slušali specijalno za te svrhe snimljenu muziku. Neke kompanije su u svoje programe obuke zaposlenih uvele muziku i na taj način i do $50 \%$ skratili vreme obuke. Poznato je da muzika utiče na obnavljanje sinapsi u mozgu te i naj način doprinosi boljem pamćenju.

U svom radu "Aplikativnost muzike u radnom okruženju menadžera", Dušan Smiljanić ${ }^{2}$ prenosi iskustva o tome koju vrstu muzike slušati u zavisnosti od učinka koji želimo postići. Praktično, to izgleda ovako:

Gregorijansko pevanje relaksira jer koristi prirodni ritam disanja.

Muzika Baha, Hendla, Vivaldija i Korelija podstiče na učenje i rad.

Muzika Hajdna i Mocarta poboljšava koncentraciju, memoriju i precepciju prostora.

Muzika romantizma podstiče empatiju.

Muzika impresionizma (Debisi, Ravel, Skrjabin) podstiče kreativnost.

Džez podstiče snažne emocije i kreativnost.

Rok i pop muzika podstiču na akciju.

Ambijentalna muzika podstiče relaksacionu usredsređenost.

Hevi metal, grandž, hip-hop, rep utiču na aktivnije ispoljavanje sopstvene ličnosti.

\section{Klasična muzika povećava produktivnost.}

Sprovođena su mnoga istraživanja muzike kao procedure za uvođenje u raspoloženje. Znamo da muzika nekada može poboljšati naše raspoloženje, a nekada će nas deprimirati.

Jednostavni model, koji ovom prilikom želimo da predstavimo, a koji su postavili Margerison i McCann ${ }^{3}$, može biti koristan u odabiru muzike za trening menadžment timova. Opredelili smo se za izbor klasične muzike jer je to upravo ona vrsta muzike čije kvalitete prepoznaju i prihvataju sve

2 Smiljanić, D.: Aplikativnost muzike u radnom okruženju menadžera; magistarski rad, Fakultet za menadžment, Novi Sad, 2007.

3 Izvor: www.tms.com.au kulture. Pridržavajući se osnovnih principa, ovaj model možemo koristiti i uz primene neke druge vrste muzike, u zavisnosti od učesnika u radionici koja se sprovodi.

Ovaj model, muziku deli na dve kategorije: energičnu ili relaksirajuću i u zavisnosti od toga da li fokus usmerava na mogućnosti ili na prepreke.

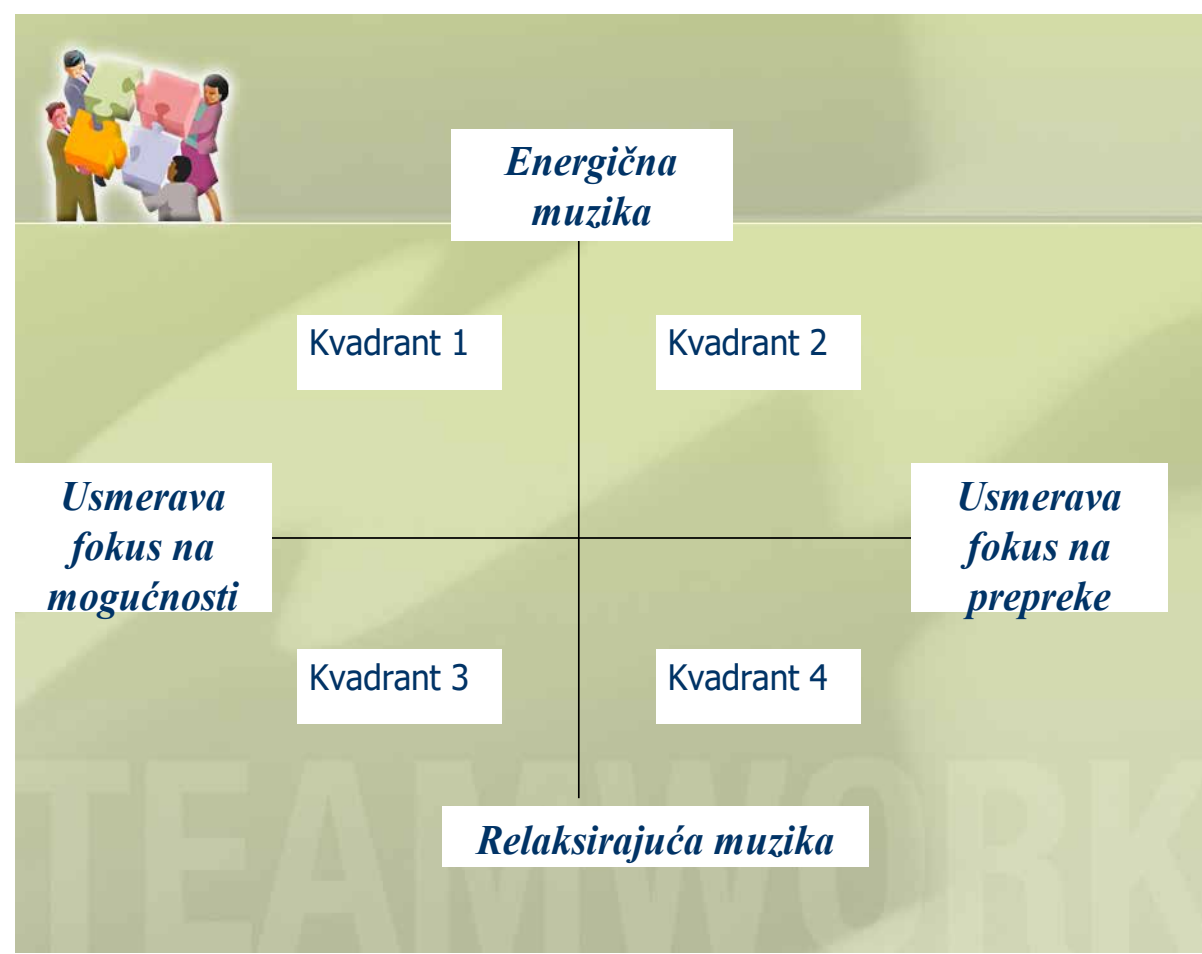

Muzika iz Kvadranta 1 je muzika sa bržim ritmom (većim od 100 otkucaja u minuti). Pomaže nam da se fokusiramo na mogućnosti i izaziva dobro raspoloženje. Često se osećamo energično, pozitivno i optimistično bar za neko vreme kada slušamo ovu vrstu muzike. Lični ukusi u većini slučajeva variraju u zavisnosti od godina ali primeri muzike predložene od strane ljudi koji su učestvovali na nekoj od ovakvih radionica su:

Four Seasons - Aleegro Movement (Vivaldi)

Brandenburg ConcertoNo2 (Bach)

Toccata and Fugue in D Minor (Bach)

Muzika iz Kvadranta 2, ima sporiji ritam od muzike iz prethodnog

HUMANISTIKA - Vol. 2. Broj 4 - Oktobar 2018. 
kvadranta (80-100 otkucaja u minuti) i u suštini je složenija muzika. Ponekad se opisuje kao moćna, dramatična, duševna i veličanstvena muzika. Dozvoljava nam da osetimo sve probleme ovoga sveta i postanemo introspektivni. U moru dobrih primera klasične muzike koja odgovara odgovara ovom kvadrantu izdvajamo:

Ride of the Valkyries (Wagner)

Arrival of the Queen of Sheba (Handel),

i uključujemo i neka dela popularne muzike kao što su Yesterday (The Beatles) i većina pesama Ray Charles-a.

Muzika Kvadranta 3, fokusira se na relaksirajuću muziku koja pomaže u stvaranju mogućnosti ili ih barem čini jasnijim. Ovaj tip muzike se koristi u sakupljanju unutrašnjih slika u procesu koji zovemo mašta. Mašta je pridružena moždanom talasu frekvencijom u rasponu od 8 do $13 \mathrm{~Hz}$ i ovo stanje je poznato kao Alfa stanje. Određeni tipovi muzike, zapravo pomažu generisanju alfa ritmova i stanju dnevnog sanjarenja ili podsticanju unutrašnje vizuelizacije. Muzika ovog kvadranta ohrabruje misaono il sanjivo raspoloženje.

Čini se da ova muzika proizvodi dugotrajne uspomene i njeno puštanje dok sakupljamo informacije ili učimo može doprineti pamćenju ključnih informacija. Ova tehnika se koristi i u ubrzanom učenju. Na tržištu postoji mnogo CD-ova sa muzikom ovog kvadranta od kojih izdvajamo: The Best of Enya, Realm of the River King (David Pickvance) i Collection of Romantic Themes (Yanni).

Adagio i andante ritmovi barokne ere su takođe veoma efikasni. Neki od njih su:

Andante from Sinfonia in G, RV 149 (Vivaldi)

Piano Sonata in C\# minor Opus 27 No.2 (Beethoven)

Muzika Kvadranta 4, ima sporiji otkucaj (50-60 otkucaja u minuti) u odnosu na muziku trećeg kvadranta. Ton može imati i kvalitetne zvukove često pojačane upotrebom nižih frekvencija koje proizvode instrumenti kao što je čelo. Za neke ljude čisto "zujanje" muzike ili crkveno pevanje pomaže u stvaranju stanja relaksacije gde se pažnja usmerava na prepreke. Primeri muzike koji odgovaraju ovom kvadrantu su:

Andante from Piano Concerto No.21 (Mozart)

Adagio for Strings in G-minor (Albinoni)

Largo Sostenutofrom String Quartet No.1 (Smetana)
Muzika može biti veoma efektno sredstvo koje koristimo u kreativnim radionicama. Možete stvoriti neophodno raspoloženje za sve: od motivacije do kreativnosti. Samo zato što je važna i ozbiljna obuka, ne mora da znači da uz nju ne možemo i uživati. Šolja kafe ili čaja i malo "Always looks on the bright side of life" podiže raspoloženje učesnika, postavlja ih u lake mentalne okvire spremne da usvoje predviđene koncepte.

Dole data lista praktičnih predloga može nam pomoći u uvođenju muzike u naše kreativne radionice ${ }^{4}$ :

muzika koju puštamo dok učesnici ulaze u prostoriju obezbeđuje raspoloženje za taj dan. Treba uzeti u obzir tip učesnika i razloge zbog kojih pohađaju radionicu

muzika za grupne aktivnosti je efektnija ako je instrumentalna, dok lirična muzika odvlači pažnju učesnika sa zadatka

ako program radionice sadrži veliki broj različitih koncepata treba izabrati različitu melodiju za svaki koncept. To pomaže učesnicima da lakše zapamte teoriju, zato što imaju muzičku asocijaciju za dozivanje sećanja

uvek treba koristiti širok raspon muzičkih stilova jer su ukusi različiti. Kretanje od lako slušljive do klasične i popularne muzike će osigurati pokrivenost muzičkih ukusa većine ljudi. Naslovi i tekstovi su veoma važni jer se koriste radi naglašavanja određene tačke, poente ili nečeg drugog u teoriji.

Kao što možemo videti iz svega napisanog u ovom poglavlju, stalno učenje (kako privatno, tako i na poslu) je suština života svakog pojedinca. "U našoj novoj ekonomiji znanja, teško onima koji nisu naučili kako učiti", kaže Peter Drucker, a mi smo se ovde potrudili da damo samo par predloga.

- Literatura:

- Maksimović, M. i Smiljanić, D.: Primena muzike u obuci za timski rad, Naučni skup "Nove tendencije u menadžmentu", Univerzitet Singidunum, Beograd, 2007.

- Maksimović, M.: Timski rad u novom milenijumu, Fakultet za menadžment \& Cekom books, Novi Sad, 2006.

4 Maksimović, M.: Timski rad u novom milenijumu, Cekom books \& Fakultet za menadžment, Novi Sad, 2006.

HUMANISTIKA - Vol. 2. Broj 4 - Oktobar 2018. 
- Smiljanić, D.: Teorijski pristup problemu aplikativnosti muzike u radnom okruženju menadžera, magistarski rad, Fakultet za menadžment, Novi Sad, 2007.

Abstrakt: The music is a powerful medium and it's applied in management training program more and more every day. Music has always been a part of culture and traditions of primitive people presenting very useful mode of social communications. The simple model that we will present here could be useful in selecting music for team building. As we hold on to this basic principles, we can use this model and apply it to any kind of music, depending on the workshop participants.

Key words: Team work, music 